\title{
Hydrogen Ion Buffers and Enzymatic Activity: Myosin B Adenosinetriphosphatase ${ }^{1}$
}

\author{
R. A. MURPHY AND P. G. KOSS \\ Department of Physiology, University of Michigan, Ann Arbor, Michigan 48104 \\ Received May 6, 1968; accepted July 4, 1968
}

\begin{abstract}
The production of hydrogen ions during the hydrolysis of ATP by myosin B and the consequent fall in $\mathrm{pH}$ can produce alterations in enzymatic activity directly, or by influencing Ca ion concentrations controlled by metal-chelate systems. Adequate hydrogen ion buffer systems can limit $\mathrm{pII}$ changes wo auceptable levels. II uwever, several commonly used hydrogen ion buffers have been reported to have specific effects on contractile protein responses, and all buffers can indirectly change activity through their contributions to the ionic strength. In this study, ten potentially useful buffers suitable for $\mathrm{pH}$ control between $\mathrm{pH} 5$ and 9 were evaluated for their effects on myo$\sin$ B ATPase activity. In eontrast to previous reports, all were found to have no effect on this system if both the buffering value $\left(\Delta \mathrm{H}^{+} / \Delta \mathrm{pH}\right)$ and the ionic strength were maintained constant. Simple methods are presented for determining the total and ionized concentrations of any buffer required to meet designated criteria for $\mathrm{pH}$ control at any operating $\mathrm{pH}$.
\end{abstract}

Undesirable decreases in $\mathrm{pH}$ may occur in experimental reactions such as those involving the hydrolysis of ATP, in which there is significant hydrogen ion production (1). Reactions in the presence of metalchelate systems, used to control the concentration of activating ions such as calcium, require even more stringent $\mathrm{pH}$ control than would otherwise be necessary. For example, if ethylene glycol bis $(\beta$-aminoethyl ether)$N, N^{\prime}$-tetraacetic acid (EGTA) is used to buffer Ca ion concentrations, a drop in $\mathrm{pH}$ of 0.1 unit may lead to a $50 \%$ increase in the $\mathrm{Ca}$ ion concentration. These considerations emphasize the importance of using optimal hydrogen ion buffer systems for investigations of the ATPase activity of contractile protein systems.

The suitability of any particular buffer for a given reaction depends on a variety of factors (2). Of major importance is whether the buffer can provide the required $\mathrm{pH}$ control at the desired operating $\mathrm{pH}$ and at con-

${ }_{1}$ This investigation received support from the Michigan Heart Association and USPHS grant HE-03756. centrations which do not increase the ionic strength above permissible values. However, it is also important that the buffer have no side effects which limit its usefulness in a paricular system. Previous work suggests that the response of an enzyme system may be influenced by the buffer substance employed (2). Several widely used hydrogen ion buffers are thought to affect the responses of contractile protein systems $(3,4)$.

The present investigation was prompted by the need to identify a series of hydrogen ion buffers with $\mathrm{p} K_{a}$ values in the 6 to 8 range and which had no side effects on the ATPase activity of myosin B. Ten buffers were examined under conditions which eliminated two complicating variables in the studies quoted above: differences in (i) the pH-stabilizing capacity of the buffers, and (ii) the ionic strength, due to the degree of ionization of the buffers. The $\mathrm{pH}$ dependence of myosin B ATPase activity at low ionic strength was also determined, independent of complications introduced by the characteristies of the individual buffers. A 
TABLE I

Hydrogen Ion Buffer Solutions at a Constant Buffering Value of $-20, \mathrm{PH} 7.0$, and $25^{\circ} \mathrm{C}$

\begin{tabular}{|c|c|c|c|c|c|}
\hline \multirow{3}{*}{ Trivial name } & \multirow{3}{*}{ Chemical name* } & \multirow{3}{*}{$\mathrm{pK}_{a} \dagger\left(25^{\circ} \mathrm{C}\right)$} & \multicolumn{3}{|c|}{ millimolar } \\
\hline & & & \multirow{2}{*}{$\begin{array}{l}\text { [Total } \\
\text { buffer] } \\
\text { (eq. } 2 \text { ) }\end{array}$} & \multicolumn{2}{|c|}{$\begin{array}{l}\text { [Buffer with } \\
\text { net charge] }\end{array}$} \\
\hline & & & & (eq. 3) & (eq. 4) \\
\hline Histidine & L-Histidine $\mathrm{l}^{\mathrm{l}, 2}$ & $5.97^{c}$ & 117 & & 9 \\
\hline MES & 2-(N-Morpholino)ethanesulfonic acid ${ }^{1}$ & $6.09^{a}$ & 93 & 84 & \\
\hline Carnosine & $\beta$-Alunyl-L-histidine ${ }^{3}$ & $6.83^{c}$ & 36 & & 15 \\
\hline Imidazole & Imidazole 4 & $7.09^{b}$ & 35 & & 20 \\
\hline MOPS & Morpholinopropanesulfonic acid ${ }^{1}$ & $7.10^{b}$ & 36 & 16 & \\
\hline TES & $\begin{array}{l}N \text {-Tris (hydroxymethyl)methyl-2-aminoeth- } \\
\text { anesulfonic acid }{ }^{1}\end{array}$ & $7.40^{\prime \prime}$ & 44 & 13 & \\
\hline HEPES & $\begin{array}{l}N-2 \text {-Hydroxyethylpiperazine- } N^{\prime}-2 \text {-ethanesul- } \\
\text { fonic acid }{ }^{1}\end{array}$ & $7.48^{a}$ & 48 & 12 & \\
\hline Tricine & $N$-Tris (hydroxymethyl)methylglycine ${ }^{1}$ & $8.04^{a}$ & 119 & 10 & \\
\hline Tris & 2-Amino-2-hydroxymethyl-propan-1,3-diol ${ }^{1}$ & $8.14^{a}$ & 145 & & 135 \\
\hline Bicine & $N, N$-Bis(2-hydroxyethyl $)$ glycine $^{2}$ & $8.26^{a}$ & 185 & 9 & \\
\hline
\end{tabular}

* Source: ${ }^{1}$ Calbiochem; ${ }^{2}$ Sigma; ${ }^{3}$ Nutritional Biochemicals; ${ }^{4}$ Eastman Organic Chemicals.

$\dagger$ Reference: ${ }^{a}$ Good et al. (2); ${ }^{b}$ by titration; ${ }^{c}$ Greenstein and Winitu (6).

preliminary report on this investigation has been presented (5).

\section{MATERIALS AND METHODS}

The buffers studied were selected on the basis of availability in pure form, reasonable solubility, and $\mathrm{p} K_{a}$ values in the 6 to 8 range. The buffers most frequently used in studies of the contractile proteins are included. Table I lists these buffers, together with their trivial names and the values for $\mathrm{p} K_{a}$. Since the $\mathrm{p} K_{a}$ value depends on temperature and, to a lesser degree, buffer concentralion, the data listed are limited in accuracy to conditions closely approximating those used in the present investigation.

Calculations of tolal and ionized buffer concentrations. To avoid differences in $\mathrm{pH}$-stabilizing capacity of the buffers tested, all comparisons were made using those buffer concentrations necessary to give identical buffering values. The buffering value of a solution may be defined as $\Delta \mathrm{H} / \Delta \mathrm{pH}$, where $\Delta \mathrm{H}$ is the quantity of hydrogen ions added to the solution and $\Delta \mathrm{pH}$ is the change in $\mathrm{pH}$ brought about (7). A decision as to a satisfactory buffering value depends on the quantity of hydrogen ions which would be produced during the course of an experimental reaction and also on the maximum acceptable change in $\mathrm{pH}$. Hydrogen ion production depends on a number of factors, but one would not ordinarily permit more than $20 \%$ hydrolysis of the total substrate present. Thus with $5 \mathrm{~mm} \mathrm{ATP}$, the production of inorganic phosphate would be limited to $1 \mathrm{~mm}$, and that would equal the maximum hydrogen ion produc- tion (1). Under ordinary circumstances at $\mathrm{pH}$ values below 8 , hydrogen ion production due to ATP splitting would be less. Chelation of divalent metal cations by ATP may additionally result in hydrogen ion liberation. If, for example, the maximum drop in $\mathrm{pH}$ which is acceptable in an experiment is $-0.05 \mathrm{pH}$ unit, an effective buffering value can be calculated where $\Delta \mathrm{H} / \Delta \mathrm{pH}=1 \mathrm{~mm} /-0.05$ pH unit $=-20$. This calculation assumes a high hydrogen ion production. Clearly, a buffering value of -20 would provide more effective $\mathrm{pH}$ control than would be required in many experimental situations (including those of the present study). Since any side effects of a buffer can best be assayed by using a range of buffer concentrations, comparisons were made at concentrations corresponding to buffering values of $-20,-10,-5$, and -2.5 .

The concentration of any buffer required to produce the desirer buffering value is a function of the $\mathrm{pH}$ of the solution and the $K_{a}$ of the buffer. This concentration can be readily calculated, assuming that the buffer behaves like a weak acid and that only one dissociation is involved in the hydrogen ion equilibrium. The equilibrium conditions at the beginning and end of a reaction are given by:

$$
K_{a}=\frac{[\mathrm{H}]_{i}[\mathrm{~A}]_{i}}{[\mathrm{HA}]_{i}}=\frac{[\mathrm{H}]_{f}[\mathrm{~A}]_{f}}{[\mathrm{HA}]_{f}}
$$

where $\quad K_{a}=$ acid dissociation constant for the buffer (corrected for temperature and concentration),

$[\mathrm{H}]_{i}$ and $[\mathrm{H}]_{f}=$ initial and final hydro. gen ion concentrations, 
$[A]_{i}$ and $[A]_{f}=$ initial and final concentrations of dissociated buffer (basic form),

$[\mathrm{HA}]_{i}$ and $[\mathrm{HA}]_{f}=$ initial and final concentrations of undissociated buffer (acidic form)

The difference between initial and final states is brought about by the addition of a quantity of hydrogen ions $=\Delta \mathrm{H}$. In both the initial and final states, the total concentration of buffer $(=[\mathrm{HA}]+$ [A]) is constant. From equation 1 expression 2 can be obtained.

[total buffer]

$$
\begin{aligned}
& =[\mathrm{HA}]+[\mathrm{A}] \\
& =\frac{(\Delta \mathrm{H})\left(K_{a} /[\mathrm{H}]_{i}+1\right)\left(K_{a} /[\mathrm{H}]_{f}+1\right)}{\left(K_{a} /[\mathrm{H}]_{i}\right)-\left(K_{a} /[\mathrm{H}]_{f}\right)}
\end{aligned}
$$

The buffer concentration required to produce any given buffering value can be calculated by substituting the desired values into equation 2 . For example, to achieve a buffering value limiting the $\mathrm{pH}$ drop from 7.00 to 6.95 on the production of $1 \mathrm{~mm}$ hydrogen ions, substitution of the relevant figures $\left(\Delta \mathrm{H}=1 \mathrm{mM},[\mathrm{H}]_{i}=10^{-7.00} \mathrm{M}[\mathrm{H}]_{j}=10^{-6.95}\right.$ M, $K_{a}=$ appropriate value for the buffer and conditions) in equation 2 gives the desired buffer concentration.

It is necessary also to calculate the concentration of the buffer which bears a net ionic charge in the reaction medium so that the ionic strength can be adjusted to a constant known value by $\mathrm{KCl}$ addition. The calculation depends on the structure of the buffer. In instances in which the acceptance of a hydrogen ion yields a zwitterion (e.g., MES, MOPS, TES, HEPES, Tricine, Bicine), the net ionic charge is zero in the acidic form. The concentration of buffer with a net (negative) charge falls with decreasing $\mathrm{pH}$, as is given by equation 3 .

[buffer with net charge]

$$
=\frac{[\text { total buffer }]\left(K_{a} /[\mathrm{H}]_{i}\right)}{1+K_{a} /[\mathrm{H}]_{i}}
$$

In other cases, the acceptance of a hydrogen ion by a $z$ witterionic or nonpolar molecule produces a net (positive) charge in the acidic form of the buffer (histidine, carnosine, imidazole, Tris). With these buffers, the concentration of buffer with a net ionic charge increases with a decrease in $\mathrm{pH}$ and is given by:

[buffer with net charge]

$$
=[\text { total buffer }]-\frac{\text { tutal buffer }]\left(K_{a} /[\mathrm{H}]_{i}\right)}{1+K_{a} /[\mathrm{H}]_{i}}
$$

The solutions to equations 2 to 4 are laborions if they must be applied to a variety of buffers over a range of $\mathrm{pH}$ values. In the present study an IBM 7090 computer was programmed in MAI) language to carry out the necessary computations. Inspection of equations 2 to 4 reveals that a furction relating $K_{a}$ and $[\mathrm{H}]$ to the desired concentrations of total and ionized buffer could be used for simple graphic solution of the equations. The desired function is given by the relationship: $K_{a} /[H]=$ antilog $\left(\mathrm{p} K_{a}-\mathrm{pH}\right)$ where $[\mathrm{H}]$ is determined by the operating $\mathrm{pH}$ of the reaction and may be taken as equal to $[\mathrm{H}]_{i}$. The computer-generated solutions to equations 2 to 4 are plotted in Figure 1 as a function of $\left(\mathrm{p} K_{a}-\mathrm{pH}\right)$ with the numerical values of the ordinate based on a buffering value of -20 . For any given buffer, substracting the desired operating $\mathrm{pH}$ from the $\mathrm{p} K_{a}$ of that buffer allows one to read from the upper U-shaped curve in Figure 1 the total buffer concentration required to give a buffering value of -20 . A buffer solution of this concentration will limit to $0.05 \mathrm{pH}$ units the drop in $\mathrm{pH}$ resulting from the production of 1 mm hydrogen ions. The lower curves allow the concentration of buffer bearing a net ionic charge to be similarly obtained, the appropriate curve being determined by whether the charged form of the buffer is basic or acidic. If a lower buffering value would be adequate, the numerical values on the ordinate of Figure 1 may be scaled down (i. e., one-half the indicated concenirations correspond to a buffering value of -10 ).

Myosin B: A myosin B (natural actomyosin) preparation was obtained from homogenized rabbit skeletal muscle extracted 12 to 18 hours with $0.6 \mathrm{M} \mathrm{KCl}+5 \mathrm{~mm} \mathrm{NaHCO}_{3}$ (pH 7.5). The extraction solution was freed of nonsoluble material and diluted to $\mu=0.075$ to precipitate the myosin B. Three additional precipitation cycles were carried out, and the final precipitate was dissolved in $0.6 \mathrm{~m} \mathrm{KCl}+1 \mathrm{~mm} \mathrm{NaHCO}_{3}$ and cenrifuged for $30 \mathrm{~min}$ at $40,000 \mathrm{~g}$. The purified myosint $B$ solution was mixed with an equal volume of double-distilled glycerol and stored at $-20^{\circ} \mathrm{C}$.

A'T'Pase activity determinations: The protein content of myosin B suspensions, washed free of glycerol, was determined by the micro-kjeldahl method using the conventional protein factor of 6.25 . Reactions were carried out at $25 \pm 0.1^{\circ} \mathrm{C}$ in the following medium: $0.3 \mathrm{mg}$ myosin $\mathrm{B} / \mathrm{ml}, 0.1$ $\mathrm{mM} \mathrm{CaCl}{ }_{2}, 5 \mathrm{~mm} \mathrm{MgATP}, \mathrm{KCl}$ to give $\mu=0.1$, and the buffer concentration required to give the desired buffering value at the operating $\mathrm{pH}$. All ion additions to the reaction medium and the major ionic complexes were taken into account in calculating the ionic strength. The buffer concentrations bearing a net ionic charge were calculated by equation 3 or 4 and checked by titration of the 


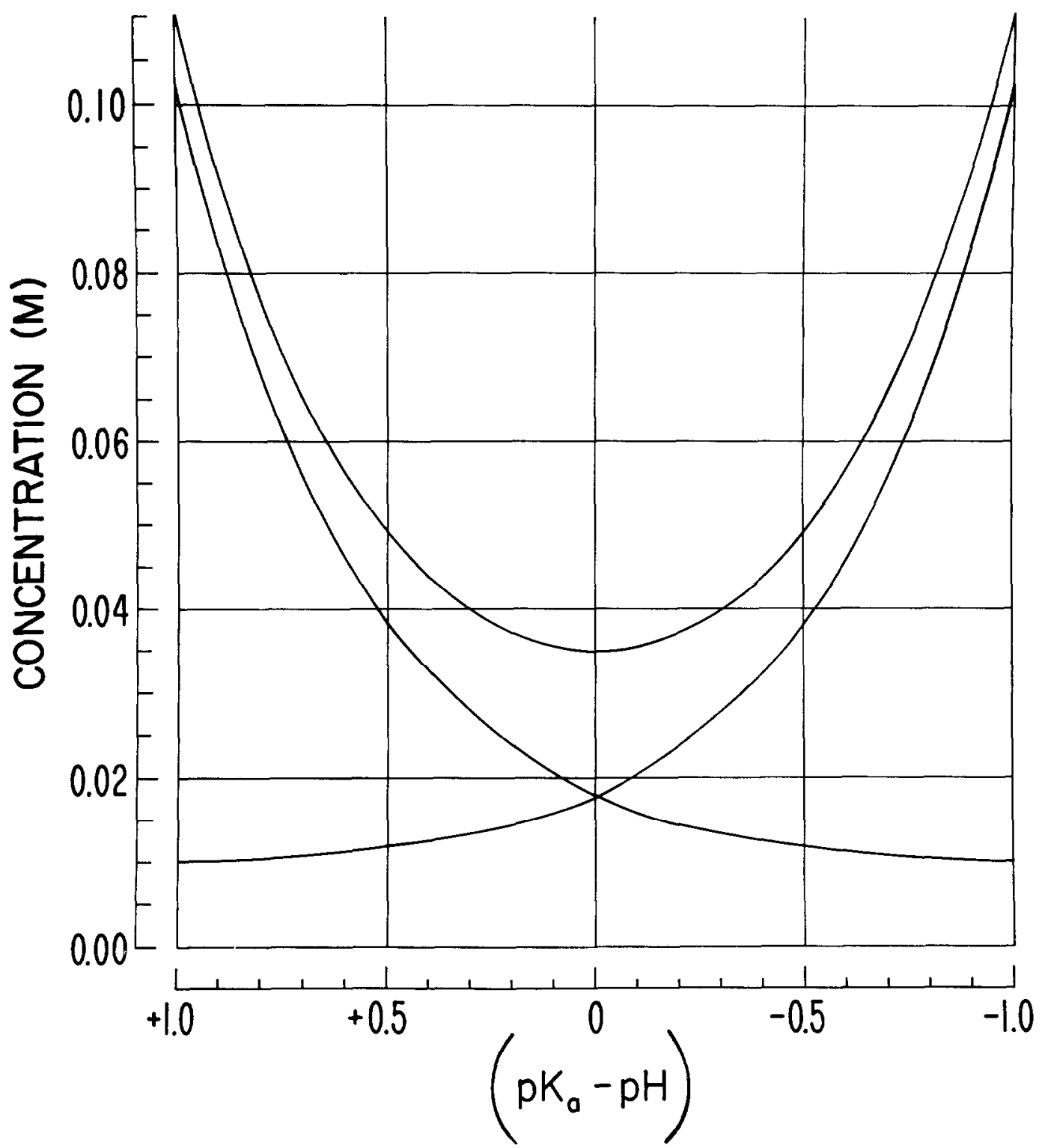

FIG. 1. Total buffer and charged buffer concentrations corresponding to a buffering value of -20 , as a function of the buffer $\mathrm{p} K_{a}$ minus the desired operating $\mathrm{pH}$. After determining $\left(\mathrm{p} K_{a}-\mathrm{pH}\right)$, the total buffer concentration required can be read from the upper U-shaped curve (corresponding to equation 2). The curve descending to the left (equation 3 ) and that descending to the right (equation 4) define the concentration of buffer molecules bearing a net charge as a function of $\left(\mathrm{p} K_{a}-\mathrm{pH}\right)$, and the choice of curve depends on whether the charged form of the buffer is basic (equation 3) or acidic (equation 4) (see text). To obtain the total and charged concentrations of a buffer necessary to give buffering values other than -20 , multiply the concentrations given on the ordinate by the fraction of -20 which gives the desired buffering value.

buffer stock solutions. $\mathrm{MgCl}_{2}$ and ATP were combined and the $\mathrm{pH}$ was adjusted to the desired value before the mixture was added to the reaction medium to avoid the $\mathrm{pH}$ drop associated with chelation of magnesium by ATP ions. A Radiometer model PHM 4e $\mathrm{pH}$ meter was used for all titrations and $\mathrm{pH}$ measurements. ATP was obtained as the disodium salt from Sigma Chemical Co. and 


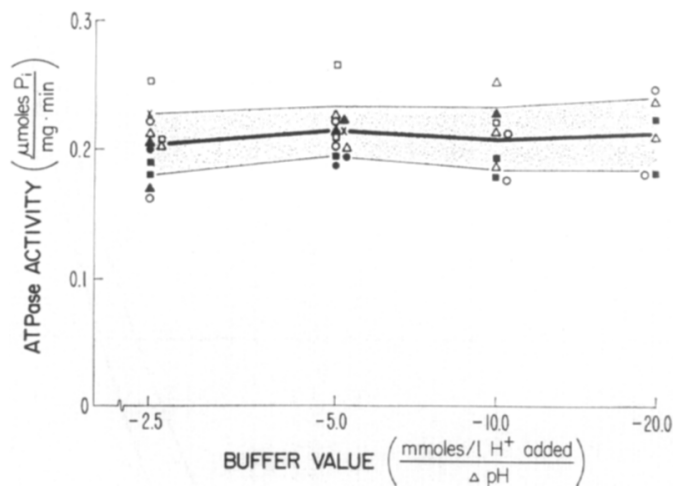

FIg. 2. Basic rate (4-8 min) of myosin B ATPase activity over an 8-fold range of buffering values (plotted on a $\log$ scale) in the presence of a variety of buffers. The heavy line connects the average ATPase activity for all determinations at each buffering value, with the shaded area indicating \pm 1 standard deviation. Conditions: 0.3 $\mathrm{mg} \operatorname{myosin} \mathrm{B} / \mathrm{ml}, 0.1 \mathrm{~mm} \mathrm{CaCl}{ }_{2}, 5 \mathrm{~mm} \mathrm{Mg-ATP}$, $\mathrm{KCl}$ to give $\mu=0.1$; buffer concentrations as required to provide the indicated buffering value at pH $7.0,25^{\circ} \mathrm{C}(O$ HEPES, - Tris, 1 histidine, $\square$ Bicine, $\triangle$ MES, $\triangle$ TES, $\times$ Tricine). Plotted points for nearly identical experimental ATPase determinations which would be superimposed are offset on the abcissa, for clarity.

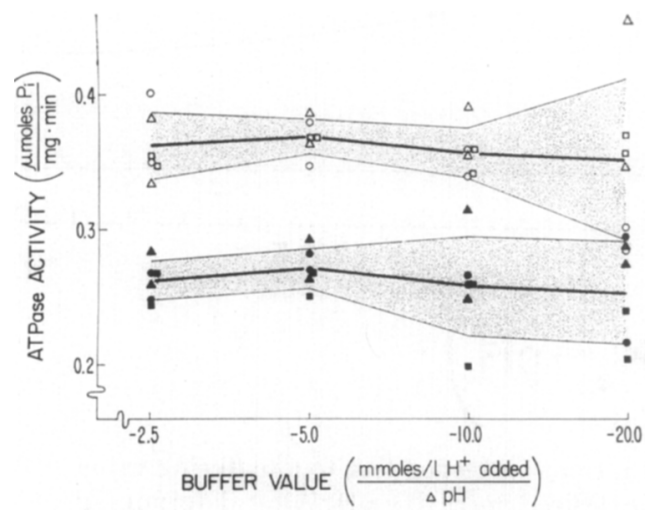

FIG. 3. Initial (0-4 $\mathrm{min}$ ) and basic (4-8 $\mathrm{min}$ ) rates of myosin B ATPase activity over an 8 -fold range of buffering values with several buffers having $\mathrm{p} K_{a}$ values near 7 . Conditions as in Figure 2. (Open symbols, initial rates; closed symbols, basic rates; 0 , imidazole; $\square, \boldsymbol{M}$ MPS; $\triangle, \boldsymbol{\Lambda}$ HEPES.)

passed through Dowex 50 ( $\mathrm{Na}$ form) to remove divalent metal cation contaminants (8). The reactions were stopped by the addition of an equal volume of $2 \%$ trichloroacetic acid. Inorganic phos-

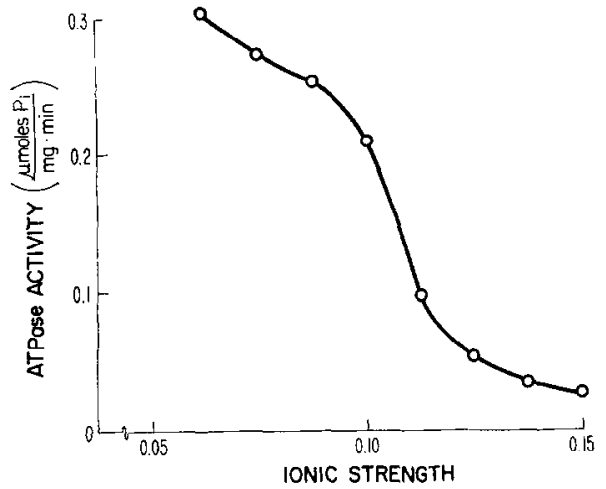

Frg. 4. Basic rate (4-8 $\mathrm{min}$ ) of myosin B ATPase activity as a function of ionic strength. Conditions: $0.3 \mathrm{mg}$ myosin $\mathrm{B} / \mathrm{ml}, 0.1 \mathrm{~mm} \mathrm{CaCl}_{2}$, $5 \mathrm{~mm} \mathrm{Mg}$-ATP, $44 \mathrm{mM}$ TES (buffering value = $-20), \mathrm{pH} 7.0,25^{\circ} \mathrm{C}$; varying additions of $\mathrm{KCl}$ to give ionic strength values indicated.

phate was measured by the method of Rockstein and Herron (9).

\section{RESULTS}

The myosin B ATPase activity was unaffected by the nature or the concentration of hydrogen ion buffer present. In Figures 2 and 3, myosin B ATPase activity in the presence of nine buffers $\left(\mathrm{pH} 7.0, \mu=0.1,25^{\circ} \mathrm{C}\right.$ ) is plotted as a function of buffering value. The actual concentration of each buffer required to achieve a given buffering value is different. For comparative purposes the concentrations for a buffering value of -20 at $\mathrm{pH} 7.0$ are listed in Table $\mathrm{I}$. It is apparent that not all buffers could be used at a buffering value of -20 at $\mathrm{pH} 7$, since the concentration of some buffers bearing a net charge would lead to ionic strengths above 0.1 . In Figure 3, the upper heavy line is the average initial ( 0 to $4 \mathrm{~min}$ ) rate of ATP splitting, which includes the so-called "initial burst" $(10,11)$, Over the concentration range employed for each buffer, there were no significant systematic changes in either the initial or basic rates of ATPase activity attributable to side effects of any individual buffer. Similar results were obtained with carnosine (not illustrated), although this dipeptide is too expensive for consideration as a buffer. The higher basic rate of activity in the experiments depicted in Figure 3 reflects a difference in myosin B preparations used. The 


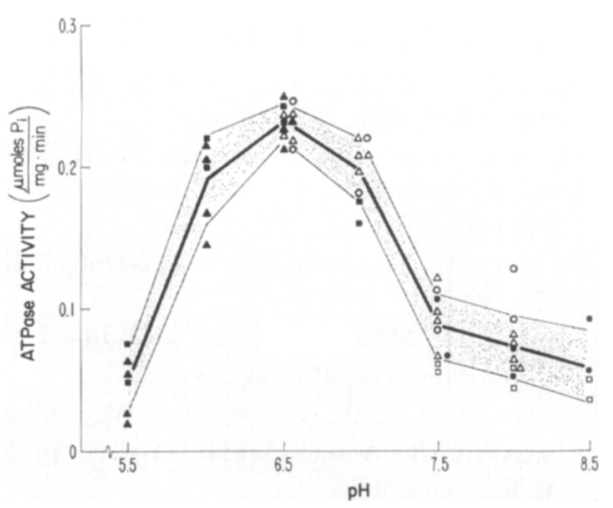

FIG. 5. Basic rate (4-8 $\mathrm{min})$ of myosin B ATPase activity as a function of $\mathrm{pH}$ at constant buffering value $(-20)$ and ionic strength $(0.1)$. Shaded area indicates \pm 1 sD from average activity at each $\mathrm{pH}$ value. Conditions: $0.3 \mathrm{mg}$ myosin $\mathrm{B} / \mathrm{ml}, 0.1 \mathrm{mM} \mathrm{CaCl}{ }_{2}, 5 \mathrm{~mm} \mathrm{Mg}-\mathrm{ATP}, \mathrm{KCl}$ to give $\mu=0.1$, buffer concentrations as required to provide a buffering value of -20 at the indicated $\mathrm{pH}$ values, $25^{\circ} \mathrm{C}$ ( $\mathrm{HEPES}$, Tris, $\square$ Bicine, histidine, $\triangle$ TES, $\triangle$ MES). Plotted points for nearly identical experimental ATPase determinations which would be superimposed are offset on the $\mathrm{pH}$ axis.

inclusion of HEPES in both series of experiments serves as a control.

Figure 4 illustrates the well-known sensitivity $(12-15)$ to changes in ionic strength of myosin B ATPase activity in the region of $\mu=0.1\left(\mathrm{pH} 7.0,25^{\circ} \mathrm{C}\right)$ when the $\mathrm{pH}$-stabilizing capacity is high and constant (buffering value $=-20$ ). Small errors in the $\mathrm{p} K_{\text {a }}$ value used to calculate the concentration of buffer bearing a net charge (equations 3 and 4) lead to systematic errors in the adjustment of the ionic strength. Since the total ionic strength depends largely on the buffer (and less on added $\mathrm{KCl}$ ) at higher buffering values, the increased scatter in ATPase activity measurements at a buffering value of -20 (Fig. 3) reflects these systematic errors.

The availability of a series of buffers with no side effects on the myosin B ATPase activity prompted a carefully controlled $\mathrm{pH}$ dependence study of this enzyme. Figure 5 illustrates an experiment in which $\mathrm{pH}$ was varied and a variety of buffers appropriate to each $\mathrm{pH}$ range was used to maintain a constant high buffering value of -20 with ionic strength adjusted to 0.1 at $25^{\circ} \mathrm{C}$. A single broad activity optimum was found between $\mathrm{pH} 6$ and 7 with sharp declines in activity at lower and higher $\mathrm{pH}$ values. The lack of specific effects of individual buffer substances on ATPase activity over a wide $\mathrm{pH}$ range is evident in Figure 5. The broad optimum shows that the myosin B ATPase activity would be little affected by small decreases in $\mathrm{pH}$ below $\mathrm{pH}$ 7. This explains why large differences in buffering value had no discernible effects on myosin B ATPase activity at $\mathrm{pH} 7$ (Figs. 2 and 3 ).

\section{DISCUSSION AND CONCLUSIONS}

Any buffer affects both the hydrogen ion concentration and the ionic strength of the solution in which it is used. In assays sensitive to $\mathrm{pH}$ or ionic strength changes, failure to control these factors can produce the appearance of buffer-induced modifications of activity. In particular, the $\mathrm{pH}$ dependence of an enzyme cannot be defined unambiguously if experimental variations in the hydrogen ion concentration alter the ionic strength. In the case of myosin B ATPase activity, no buffer was found to affect the activity, per se. Many of the buffers tested have been reported to have side effects on other enzyme systems (2), but the comparisons did not take into account differences in buffering value or ionic strength. It has been reported that histidine, carnosine, and imidazole stimulate myofibrillar ATPase activity at $\mathrm{pH} 7.0$ in the absence of calcium ions (3). Furthermore, histidine, carosine, and Tris apparently accelerate the rate or extent of ATP induced shortening of glycerinated muscle fibers at $\mathrm{pH} \&$ (4). It appears likely that the observed effects of these buffers on contractile protein responses, at least in part, reflect relative changes in the ionic strength or $\mathrm{pH}$ of the bathing media. The ionic strength (12-15) and pH (16) dependence of myosin $B$ observed agree with results given in earlier reports of experiments performed under comparable conditions.

With respect to the substances tested, the buffer of choice in the myosin B system is that which will provide the desired buffering capacity at the lowest cost. Subject to experimental verification, this may be true of many other enzyme systems. Factors such as solubility, chelate formation, stability, light 
absorption, etc. of any given buffer should be taken into consideration, although all of the materials tested were satisfactory for the experiments reported here. The cost calculation for any $\mathrm{pH}$ value can be easily made with the aid of Fig. 1 and may lead to surprising results. For example, despite a high cost per gram for highly purified imidazole, it is an economical buffer at $\mathrm{pH} 7$, the region of most effective buffering of this low molecular weight compound.

The practice of using hydrogen ion buffers to provide known buffering values in experimental media has many advantages. Attention is focused on those factors which alter the $\mathrm{pH}$ of the reaction solution (hydrogen ion production, temperature changes, chelate formation, etc.). In addition, the effects of such $\mathrm{pH}$ changes on the activity measured (whether directly, or indirectly through induced alterations in ionic strength or in divalent metal cation concentrations controlled by metal chelate systems) are more easily recognized and controlled. Figure 1 (or equations 2 to 4) may be generally useful as a simple means of defining a buffer system which will provide the $\mathrm{pH}$-stabilizing capacity demanded by adequate experimental design.

\section{ACKNOWLEDGMENTS}

The helpful suggestions and support extended by Dr. David F. Bohr and Dr. Ruth MoVaugh are gratefully acknowledged.

\section{REFERENCES}

1. Green, I., and Mommaerts, W. F. H. M., $J$. Biol. Cheml. 202, 541 (1953).

2. Good, N. E., et al, Biochemistry 5, 467 (1966).

3. Yun, J., And Parker, C. J., Jr., Biochim. Biophys. Acta 110, 212 (1965).

4. Bowen, W. J., Arch. Biochem. Biophys. 112, 436 (1965).

5. Koss, P. G., Murphy, R. A., And Bohr, D. F., Federation Proc. 27, 323 (1968).

6. Greenstein, J. P., And Winitz, M., "Chemistry of the Amino Acids," Vol. 1, p. 498. Wiley, New York (1961).

7. Mahler, H. R., and Cordes, E. H., "Biological Chenisiry," p. 191. Harper \& Row, New York (1966).

8. Seidel, J. C., and Gergely, J., J. Biol. Chem. 238, 3648 (1963).

9. Rockstein, M., and Herron, P. W., Anal. Chem. 23, 1500 (1951).

10. Weber, A., and Hasselbach, W., Biochim. Biophys. Acta 15, 237 (1954).

11. Tonomura, Y., Kitagawa, S., and YoshiMURA, J., J. Biol. Chem. 237, 3660 (1962).

12. Maroyama, K., and Ishikawa, Y., J. Biochem. 55, 110 (1964).

13. Fanburg, B., Finkel, R. M., and Martonost, A., J. Biol. Chem. 239, 2298 (1964).

14. Eisenberg, E., and Moos, C., Nature 211, 529 (1966).

15. Hasselabeh, W., Z. Naturforsch. 7b, 163 (1952).

16. Watanabe, S., and Yasut, T., J. Biol. Chem. 240, 105 (1965). 